\title{
Crescimento da parte aérea e raiz do meloeiro adubado com fertilizante orgânico ${ }^{1}$
}

\author{
Shoot and root growth in the muskmelon when fertilised with organic fertiliser
}

\author{
Elis Regina Costa de Morais ${ }^{2 *}$ e Celsemy Eleutério Maia ${ }^{3}$
}

\begin{abstract}
RESUMO - Este estudo objetivou avaliar o efeito do fertilizante orgânico no crescimento de raiz e da parte aérea do meloeiro em função de graus dias acumulado. Foi instalado um experimento em vasos, em delineamento experimental em blocos casualizados com quatro repetições em esquema fatorial 2x6, referente a presença e ausência de fertilizante orgânico e seis épocas de amostragens $(7 ; 14 ; 21 ; 28 ; 3542$ dias), totalizando 48 parcelas experimentais. Para cada amostragem determinou-se número de folhas (NF), área foliar (AF), matéria seca de raiz (MSR) e matéria seca da parte aérea (MSPA). A taxa de crescimento absoluto (TCA) divergiu em função da adubação para as diferentes características avaliadas e na presença do fertilizante orgânico, verificou-se que as somas calóricas para se obter as maiores TCA foram maiores nos tratamento que não receberam o fertilizante orgânico.
\end{abstract}

Palavras-chave: Melão. Adubos e fertilizantes orgânicos. Crescimento (Plantas).

\begin{abstract}
This study aimed to evaluate the effect of organic fertilizer on root and shoot growth in the melon as a function of accumulated growing degree days. An experiment was set up in pots, in a randomized block design, with four replications and a 2x6 factorial arrangement, corresponding to the presence and absence of organic fertilizer, and six sampling dates $(7 ; 14 ; 21 ; 28 ; 35$ and 42 days), giving a total of 48 plots. For each sample, the number of leaves (NL), leaf area (LA), root dry matter (RDM) and shoot dry matter (SDM) were determined. The absolute growth rate (AGR) differed for those traits analysed according to the type of fertilisation used and the presence of organic fertilizer, it was found that the caloric totals required to get the highest AGR were higher in those treatments that received no organic fertilizer.
\end{abstract}

Key words: Melon. Fertilizers and organic fertilizers. Growth (Plants).

\footnotetext{
*Autor para correspondência

${ }^{1}$ Recebido para publicação em 07/11/2011; aprovado em 04/12/2012

Pesquisa realizada na Universidade Federal Rural do Semi-árido/UFERSA

${ }_{2}^{2}$ Departamento de Ciências Ambientais e Tecnológicas/DCAT/UFERSA, Av. Francisco Mota, BR 110, km 47, Mossoró-RN, Brasil, 59.625-900, elisregina@ufersa.edu.br

${ }^{3}$ Bolsista do CNPq, Departamento de Ciências Ambientais e Tecnológicas/DCAT-UFERSA, Av. Francisco Mota, BR 110, km 47, Mossoró, RN, Brasil, 59625-900, celsemy@ufersa.edu.br
} 


\section{INTRODUÇÃO}

O crescimento de uma planta pode ser medido de varias maneiras. Em alguns casos, a determinação da altura é suficiente, mas, às vezes, maiores informações são necessárias, como por exemplo, o tamanho das folhas, a matéria seca total ou de órgãos individuais, como raízes, caules, folhas e frutos. A determinação da área foliar ocupa lugar de destaque, uma vez que as folhas são as principais responsáveis pela captação da energia solar e pela produção de matéria seca através da fotossíntese. Nesse sentido, a análise de crescimento objetiva descrever e interpretar o desempenho de determinada espécie, crescendo em ambiente natural ou controlado. Os índices envolvidos indicam a capacidade do sistema assimilatório das plantas em sintetizar fotoassimilados (fonte) e alocar a massa produzida para os diversos órgãos (dreno), expressando as condições morfofisiológicas da planta e quantificando a produção líquida, gerando assim a descrição clara do padrão de crescimento da planta, permitindo a comparação entre situações distintas (BARCELOS; GARCIA; MARCIEL JÚNIOR, 2007; FONTES; DIAS; SILVA, 2005).

As substâncias húmicas constituem uma fração da matéria orgânica do solo, composta por substâncias amorfas, com estruturas químicas complexas, de natureza particular e de maior estabilidade do que os materiais que as originam (FONTANA et al., 2007) e, uso dessas substâncias como fertilizante visa aumentar as atividades químicas e bioquímicas do solo (SILVA, 1995), podendo agir contra efeitos oxidativos nas plantas estressadas (O’DONNELL, 1993) além de aumentar o crescimento dos órgãos vegetais como também, melhorar o desenvolvimento do sistema radicular (SILVA et al., 2000).

Uma ferramenta importante para o estudo do crescimento, desenvolvimento e produtividade de uma cultura é o uso de modelagem matemática, pois permite, entre outros, a descrição dos processos envolvidos no sistema e a simulação de situações que tornam possível a tomada de decisões antes do começo do plantio, aproximando-se do melhor resultado possível (MULLER; BERTO; TOLEDO, 2007). Assim, informações sobre a fisiologia da planta são fundamentais para o desenvolvimento de modelos de simulação e para a compreensão das interações entre planta e ambiente. Um dos índices biometeorológicos mais utilizados para relacionar o grau de desenvolvimento de uma cultura com a temperatura do ar é o graus-dia (SCHOFFER; VOLPE, 2002).

Segundo Gadioli et al. (2000) a utilização da temperatura média do ar, em escala diária, é uma boa estimativa indireta da quantidade de energia química metabólica produzida pelo material genético. Um dos modos de medir o efeito da temperatura em plantas é determinando a quantidade de unidades calóricas $\left({ }^{\circ} \mathrm{C}\right)$, unidades térmicas de desenvolvimento (U.T.D.) ou grausdia (GD), por predizer as fases fenológicas da cultura (BAKER; REDDY, 2001). O método dos graus-dia baseia-se na premissa de que uma planta necessita de certa quantidade de energia, representada pela soma de graus térmicos necessários, para completar determinada fase fenológica ou mesmo o seu ciclo total. Admite-se, além disso, uma relação linear entre acréscimo de temperatura e desenvolvimento vegetal. Cada espécie vegetal ou variedade possui uma temperatura base, que pode variar em função da idade ou da fase fenológica da planta. É comum adotar uma única temperatura base para todo o ciclo da planta por ser mais fácil a sua aplicação (PRETT, 1992).

O presente trabalho objetivou avaliar o efeito de fertilizante orgânico no crescimento de raiz, matéria seca da parte aérea, número de folhas e área foliar do meloeiro em função de graus-dia acumulado.

\section{MATERIAL E MÉTODOS}

O solo utilizado para o experimento foi classificado como Latososolo Vermelho Amarelo (EMPRESA BRASILEIRA DE PESQUISA AGROPECUÁRIA, 2006) coletado de uma área produtora de melão na região Oeste do Estado do Rio Grande do Norte, cujo clima é classificado, segundo Koppen, como BSwh', ou seja, quente e seco; com precipitação pluviométrica bastante irregular, média anual de $673,9 \mathrm{~mm}$; temperatura de $27^{\circ} \mathrm{C}$ e umidade relativa do ar média de 68,9\% (CARMO FILHO; OLIVEIRA, 1995). O solo apresentava as seguintes características químicas na camada de 0 a $20 \mathrm{~cm}: \mathrm{pH}(\mathrm{em} \mathrm{H} 2 \mathrm{O})=7,0 ; \mathrm{K}(0,13 \mathrm{cmolc}$ $\left.\mathrm{dm}^{-3}\right) ; \mathrm{H}+\mathrm{Al}$ trocável $\left(\mathrm{cmol}_{\mathrm{c}} \mathrm{dm}^{-3}\right)=0,83 ; \mathrm{Ca}\left(\mathrm{cmol}_{\mathrm{c}} \mathrm{dm}^{-3}\right)$ $=3,10 ; \mathrm{Mg}\left(\mathrm{cmol}_{\mathrm{c}} \mathrm{dm}^{-3}\right)=0,70 ; \mathrm{Na}\left(\mathrm{cmol}_{\mathrm{c}} \mathrm{dm}^{-3}\right)=0,03$; P- Mehlich $1\left(\mathrm{mg} \mathrm{dm}^{-3}\right)=4,0$ (EMPRESA BRASILEIRA DE PESQUISA AGROPECUÁRIA, 2009).

Utilizou-se fatorial $2 \times 6$, sendo presença e ausência de fertilizante orgânico (produto comercial na forma líquida) e seis épocas de amostragem $(7 ; 14 ; 21 ; 28 ; 35$ e 42 dias). Os tratamentos foram distribuídos em blocos casualizados com quatro repetições, sendo as unidades experimentais constituídas por vasos com $18 \mathrm{dm}^{3}$ de solo onde foram semeadas quatro sementes de melão pele-desapo, cultivar Sancho. Após a germinação foi realizado o desbaste, deixando apenas uma planta por vaso.

Antes do plantio o solo recebeu adubação corretiva para elevar o teor de fósforo para $60 \mathrm{mg} \mathrm{kg}^{-1}$ utilizando MAP. A adubação de cobertura foi feita via fertirrigação, iniciando seis dias após a semeadura com aplicação diária até os 35 dias de $\mathrm{N}, \mathrm{P}_{2} \mathrm{O}_{5}$ e $\mathrm{K}_{2} \mathrm{O}$, totalizando o equivalente a $120 ; 120$ e $280 \mathrm{~kg} \mathrm{ha}^{-1}$, respectivamente. A adubação orgânica foi feita com produto comercial líquido contento $10 \%$ de carbono, $12 \%$ de ácido húmico e $3 \%$ de 
ácido fúlvico, sendo aplicados $100 \mathrm{~mL}$ por vaso no início do experimento. A aplicação de água foi feita duas vezes ao dia, sendo uma na parte da manhã e outra pela tarde, repondo a quantidade de água evapotranspirada de acordo com o peso dos vasos que foram previamente calibrados na capacidade de campo.

Durante o ciclo da cultura foram realizadas seis coletas de plantas para a realização da análise de crescimento $(7 ; 14 ; 21 ; 28 ; 35$ e 42 dias). Por ocasião da coleta, foi amostrada uma planta por repetição, cortadas rente ao solo colocadas em sacos plástico e transportadas para o laboratório, onde foram realizadas as análises, sendo o crescimento caracterizado pelo número de folhas (NF), área foliar (AF), matéria seca da parte aérea (MSPA) e matéria seca de raiz (MSR). A AF foi determinada utilizando-se um integrador de área foliar, modelo LI3100 do Licor. Após determinação da AF as folhas foram acondicionadas em sacos de papel, levadas para secar em estufa de circulação forçada à temperatura de $70^{\circ} \mathrm{C} \pm 1{ }^{\circ} \mathrm{C}$, até atingirem peso constante. Após a secagem, o material foi pesado, determinando-se a matéria seca da parte aérea (MSPA). Para a coleta das raízes utilizou-se peneira de malha $2 \mathrm{~mm}$ para separar o solo das raízes, estas também foram levadas à estufa $\left(70{ }^{\circ} \mathrm{C} \pm 1^{\circ} \mathrm{C}\right.$, ) até peso constante, pesadas e obtendo-se a matéria seca de raiz (MSR).

Para modelar as características de crescimento em função dos valores de graus-dia acumulado (GDA) foi usado o modelo logístico, equação 1 .

$$
\mathrm{Y}=\frac{\mathrm{a}}{1+e^{\mathrm{b}-\mathrm{c} \cdot \mathrm{GDA}}}
$$

Em que: GDA é graus dia acumulado (soma calórica), e, $a$, $b$ e $c$ parâmetros do modelo.

A soma calórica, em grau-dia, foi calculada de acordo com a equação 2 .

$$
\mathrm{GDA}=\sum_{i=1}^{n}\left[\left(\frac{\mathrm{T}_{\max }+\mathrm{T}_{\min }}{2}\right)-\mathrm{T}_{\mathrm{B}}\right]
$$

Em que: $\mathrm{T}_{\max }$ e $\mathrm{T}_{\text {min }}$ são a temperatura máxima e mínima diária do ar $\left({ }^{\circ} \mathrm{C}\right)$, respectivamente, Tb é a temperatura basal $\left({ }^{\circ} \mathrm{C}\right)$, usada $12{ }^{\circ} \mathrm{C}$ de acordo com Baker e Reddy (2001) e, $n$ é o número de dias após a semeadura. Os dados de temperatura máxima e mínima do ar foram obtidos da estação meteorológica localizada a aproximadamente $500 \mathrm{~m}$ da área experimental.

Com base no modelo ajustado aos dados, foram estimados os valores dos índices fisiológicos, determinando os valores da taxa de crescimento absoluto da cultura (TCA), taxa de crescimento relativo (TCR), razão de área foliar (RAF) e da taxa de assimilação líquida (TAL). ATCA foi obtida pela derivada primeira do modelo (Equação 3) e a TCR pelo quociente entre a TCA de cada característica avaliada pelos seus respectivos valores estimados em cada época de coleta (Equação 4). A RAF foi estimada pelo quociente entre AF e a matéria seca da parte aérea (MSPA) e a TAL pela razão entre TCA e AF (Equação 5). Os dados foram analisados utilizando o software SAEG desenvolvido pela Universidade Federal de Viçosa.

$$
\begin{aligned}
T C A & =\frac{\mathrm{a} \cdot \mathrm{c} \cdot e^{\mathrm{b}-\mathrm{c} \cdot \mathrm{GDA}}}{\left(1+e^{\mathrm{b}-\mathrm{c} \cdot \mathrm{GDA}}\right)^{2}} \\
\mathrm{TCR} & =\frac{\mathrm{TCA}}{Y} \\
\mathrm{TAL} & =\frac{\mathrm{TCA}}{A F}
\end{aligned}
$$

\section{RESULTADOS E DISCUSSÃO}

O modelo logístico se ajustou aos dados das características avaliadas, com coeficientes de determinação para todas as regressões superiores a 0,99. A produção de matéria seca de raiz (MSR), matéria seca da parte aérea (MSPA) e a área foliar (AF) aumentaram com o uso do fertilizante orgânico, enquanto que, para o número de folhas (NF), praticamente não houve diferença (Figura 1 e 2). A relação entre as características avaliadas com e sem o fertilizante orgânico foram de 2,01; 2,56; 1,06 e 1,23 para MSR, MSPA, NF e AF, respectivamente.

Para as características avaliadas em função GDA, verifica-se que houve crescimento inicial lento aumentado exponencialmente até atingir valor máximo em que, a partir deste houve um decréscimo, sendo que esse valor um máximo para os tratamentos sem fertilizante orgânico necessitaram de menor GDA (Figura 1 e 2). Segundo Pace et al. (1999), esse crescimento inicial lento ocorre porque as plantas gastam grande parte da energia para a fixação no solo, principalmente com a exploração deste pela emissão de raízes pela planta, sendo as raízes nesta fase o dreno preferencial dos fotoassimilados, levando à maior produção de matéria seca de raiz quando comparada com a parte aérea.

Após a fase de crescimento lento, a planta passa a ter como dreno preferencial a parte aérea e o crescimento é exponencial até atingir um valor máximo. A diminuição observada do NF no final do ciclo se deve a vários fatores, dentre os quais, a diminuição do fornecimento de água nesta época para aumentar o teor de sólidos totais ( ${ }^{\circ}$ Brix) e também devido a senescência e abscisão foliar induzida pela distribuição preferencial de assimilados em direção aos frutos, conforme citado por Benincasa (2003) e verificado para a cultura do feijão por Bastos et al. (2002). Este decréscimo no fim do ciclo da cultura do meloeiro também foi observado por Silva et al. (2005) ao relatar que 
Figura 1 - Valores de matéria seca da parte aérea na ausência (MSPAa) e presença (MSPAp) e da matéria seca de raiz na ausência (MSRa) e matéria seca de raiz na presença (MSRp), em função da soma calórica
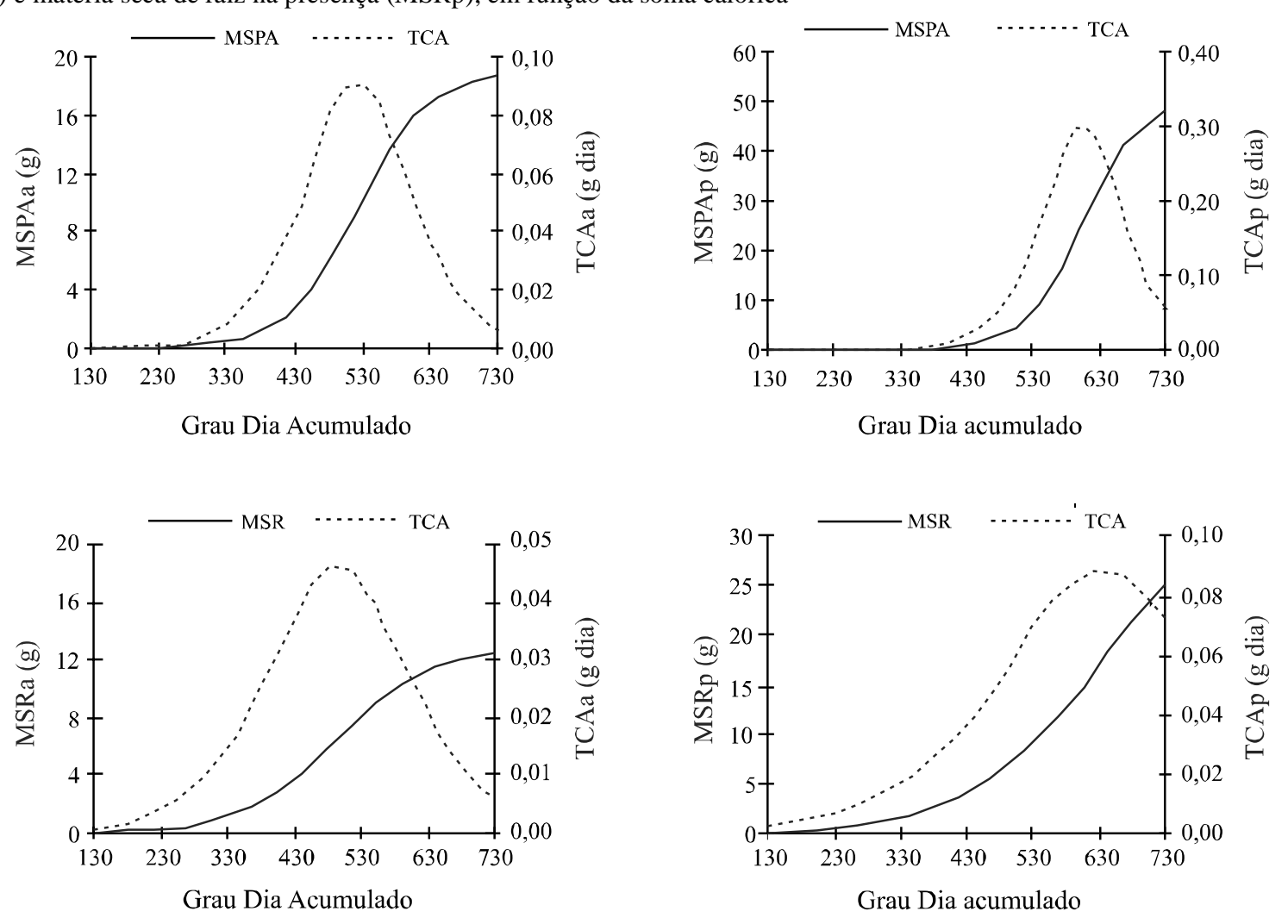

este está associado ao aumento no regime respiratório da planta, provocado pela perda de biomassa das folhas e frutos.

Com relação à estimativa da taxa de crescimento absoluta (TCA), observa-se que a eficiência da planta no crescimento diário aumentou até atingir um valor máximo, o qual divergiu em função da adubação para as diferentes características avaliadas (Figura 1 e 2). Analisando a taxa de crescimento absoluto máxima $\left(\mathrm{TCA}_{\max }\right)$ durante o período de crescimento, os valores obtidos na ausência do fertilizante orgânico foram de 0,047 e 0,099 $\mathrm{g} \mathrm{GDA}^{-1}$ para MSR e MSPA, respectivamente e 0,061 folhas GDA $^{-1}$ para $\mathrm{NF}$ e de $4,41 \mathrm{~cm}^{2} \mathrm{GDA}^{-1}$ para $\mathrm{AF}$, ou seja na presença de fertilizante orgânico a TCA ${ }_{\text {max }}$ foi superior para MSR e MSPA e inferior para NF e AF quando comparado com os tratamentos sem a adubação orgânica, sendo a soma calórica necessária para estes valores de 495; 522; 445 e 449 para MSR, MSPA, NF e AF, respectivamente.

Segundo alguns autores que trabalharam com a TCAdo NF, a taxa de emergência foliar está intimamente relacionada comafotossíntese, comotambémaTCAtambéméinfluenciada pela temperatura, porém outros fatores, tais como, radiação solar, compactação do solo, salinidade e disponibilidade de nutrientes também afetam a TCA (BENINCASA, 2003).

Além de parte dos fotoassimilados serem drenados para o fruto, também se verifica que a diminuição da TCA ocorre pela competição entre plantas (SEGINER, 2004). Em feijão, Bastos et al. (2002) verificaram a diminuição de TCA para NF e justificaram em função do início da formação de vagens e enchimento dos grãos, o que proporciona a retenção de maior número de fotoassimilados, reduzindo sensivelmente a emissão de novas folhas.

Na presença do fertilizante orgânico, verificou-se que as somas calóricas para se obter as maiores $\mathrm{TCA}_{\max }$ foram superior ao tratamento sem fertilizante orgânico. Os valores de TCA $_{\max }$ obtidos foram de 0,088 e 0,309 $\mathrm{g} \mathrm{GDA}^{-1}$ para MSR e MSPA, respectivamente. Para NF e AF, estes valores foram de 0,052 folhas $\mathrm{GDA}^{-1}$ e de 2,37 $\mathrm{cm}^{2} \mathrm{GDA}^{-1}$, respectivamente, sendo a soma calórica para estes valores de 630; 605; 504 e 548 GDA para MSR, MSPA, NF e $\mathrm{AF}$, respectivamente. Estes resultados provavelmente se devem à baixa fertilidade do solo estudado, sendo que, a aplicação do fertilizante orgânico, estimulou o crescimento das plantas pelo fornecimento de alguns nutrientes, principalmente micronutrientes (de acordo com o rótulo do produto). Alves et al. (2005), trabalhando com os mesmos produtos, em Cabissolo Háplico, de maior 
Figura 2 - Valores de matéria seca de raiz (MSR), matéria seca da parta aérea (MSPA), número de folhas (NF) e área foliar (AF) e as respectivas taxas de crescimento absoluto (TCA) em função da soma calórica na presença de fertilizante orgânico
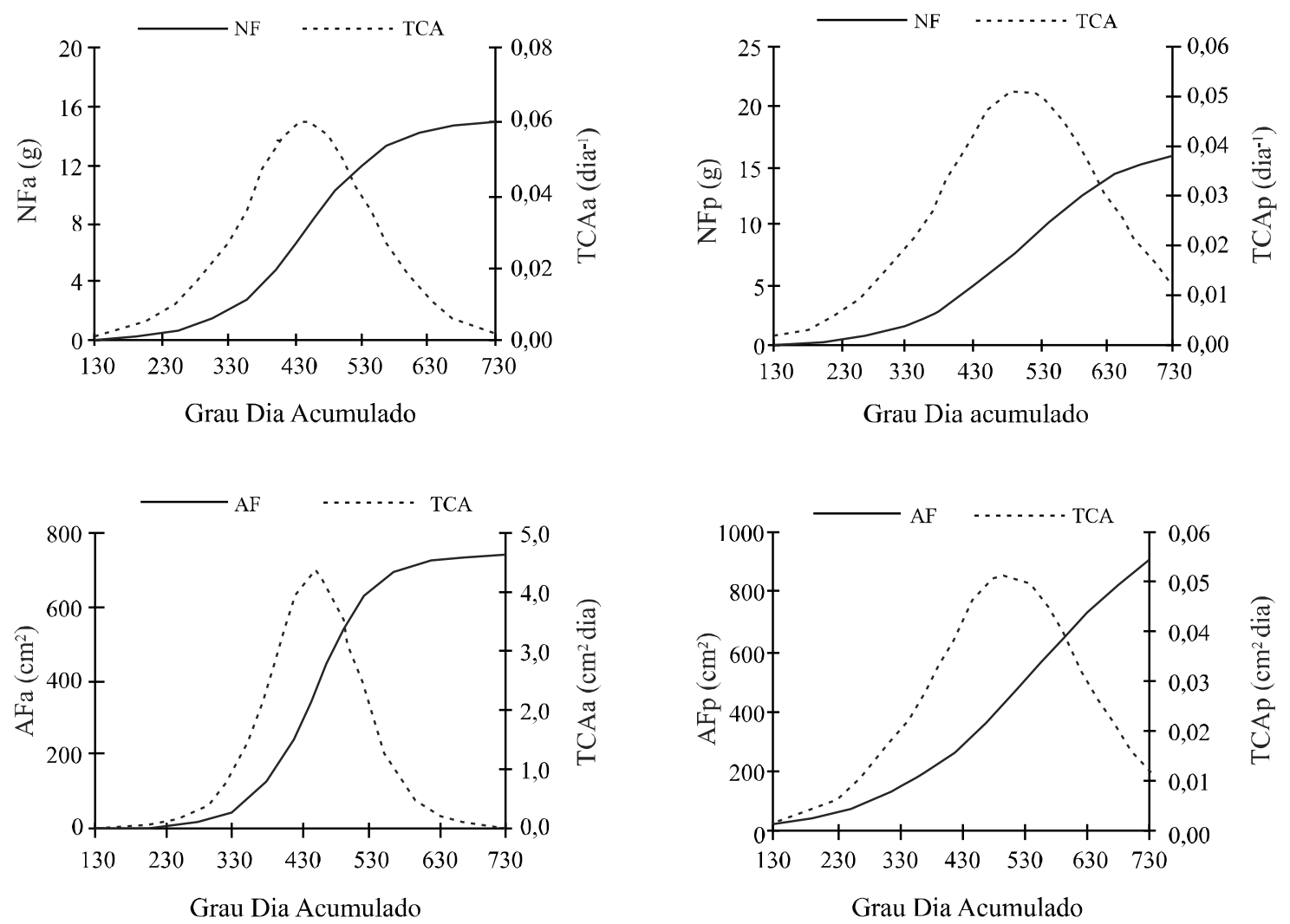

fertilidade que o Latossolo, verificaram que os efeitos não foram tão visíveis quanto neste trabalho.

Para a taxa de crescimento relativo verificou-se um período inicial de rápido acúmulo de material, seguido de uma fase de acúmulo constante, com um período final de declínio da TCR (Figura 3). Lima Júnior et al., (2004) também verificaram este comportamento de queda na taxa de crescimento relativo do melão submetido a diversos tratamentos. Essa diminuição contínua da TCR pode ser explicada pela elevação da atividade respiratória e pelo autosombreamento, cuja importância aumenta com a idade da planta. E ainda segundo Costa, Morison e Dennett (1997), a TCR pode ser afetada principalmente por dois componentes, sendo o primeiro a quantidade de fotoassimilados armazenados nas folhas em comparação com o restante da planta e, segundo, pela eficiência dos componentes assimilatórios, com isso durante o ciclo da cultura baixos valores de RAF (expressa a área útil para fotossíntese) podem ser compensados por maiores valores de TAL (CAIRO; OLIVEIRA; MESQUITA, 2008).

Para RAF, observou-se comportamento quadrático com ponto de máximo em aproximadamente 430 GDA, na ausência de fertilizante orgânico, após os valores

máximos, a RAF decresce constantemente até o final do ciclo (Figura 4a), para a presença de fertilizante orgânico a RAF foi inicialmente alta e decresceu até o final do ciclo. A RAF é uma medida relativa do aparelho assimilador, ou seja, ela representa a dimensão relativa do aparelho fotossintético, sendo bastante apropriada à avaliação dos efeitos genotípicos, climáticos e de comunidades vegetais. Este índice fisiológico expressa, também, a área foliar útil para a fotossíntese, sendo um componente morfofisiológico da análise de crescimento (BENINCASA, 2003). Dessa forma, a queda da RAF ocorre à medida que a planta se desenvolve e a potencialidade de produção de assimilação decresce, pois com o crescimento da planta, a tendência é a área foliar útil diminuir (ALVAREZ et al., 2005).

As estimativas da TAL revelou valores máximos no início do ciclo, para as plantas cultivadas na presença de fertilizante orgânico, seguido de uma queda até o final do ciclo. Para as plantas cultivadas na ausência de fertilizante orgânico, houve aumentou da TAL, até aproximadamente 7.630 GDA, e, a partir dos 740 GDA, diminui até o final do ciclo (FIG. 4b). A TAL reflete a dimensão do sistema assimilador que é envolvido na produção de matéria seca (estimativa da fotossíntese líquida) e é dependente de fatores ambientais, 
Figura 3 - Taxa de crescimento relativo na ausência (TCRa) e presença (TCRp) de fertilizante orgânico para matéria seca de raiz (MSR), matéria seca da parta aérea (MSPA), número de folhas (NF) e área foliar (AF) em função da soma calórica
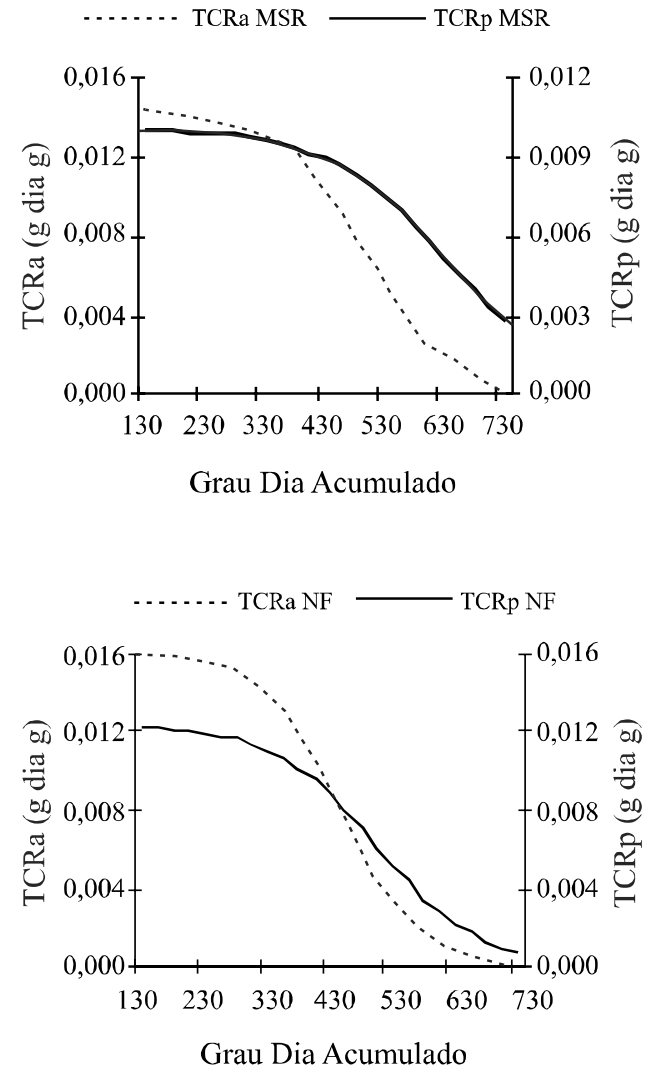
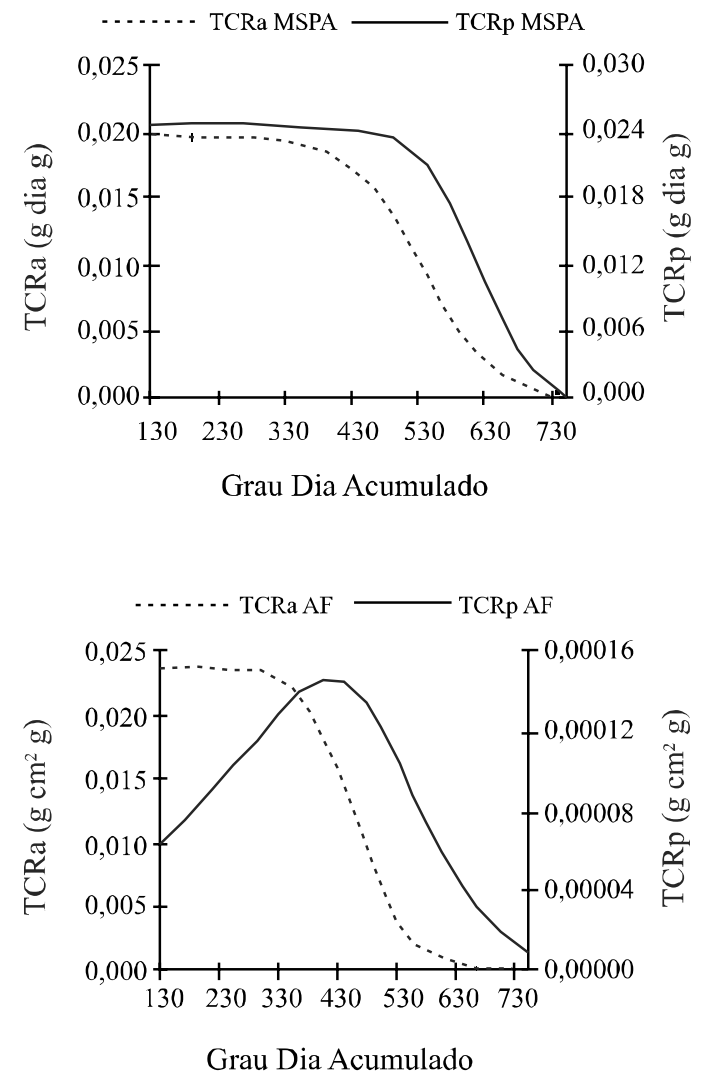

Figura 4 - Valores da Taxa de Assimilação Líquida na ausência (TALa) e presença (TALp) e da razão de área foliar na ausência (RAFa) e presença (RAFp) de fertilizante orgânico em função da soma calórica

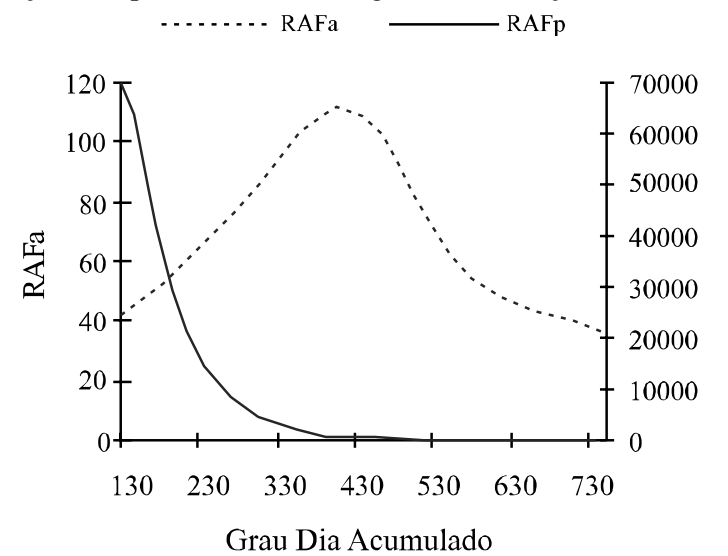

(a)

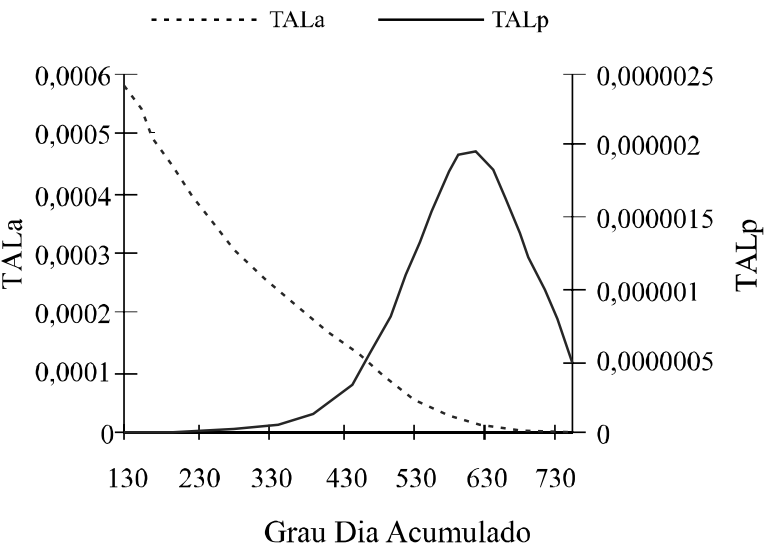

(b) principalmente da radiação solar e que, pelo efeito do autossombreamento, a TAL diminui com o aumento da área foliar e conseqüentemente, durante o crescimento da planta (CAIRO; OLIVEIRA; MESQUITA, 2008).

\section{CONCLUSÕES}

1. A TCA divergiu em função da adubação para as diferentes características avaliadas e na presença do fertilizante orgânico; 
2. As somas calóricas para se obter as maiores $\mathrm{TCA}_{\max }$ foram superiores ao tratamento sem fertilizante orgânico.

\section{REFERÊNCIAS}

ALVAREZ, R. C. F. et al. Análise e crescimento de duas cultivares de amendoim (Arachis Hypogaea L.). Acta Scientiarum. Agronomy, v. 27, n. 4, p. 611-616, 2005.

ALVES, S. S. V. et al. Crescimento de raiz do meloeiro em função de aplicação de biofertilizante. In: CONGRESSO BRASILEIRO DE OLERICULTURA, 45., 2005, Fortaleza. Anais ... Fortaleza: CBO, 2005. 1 CD-ROM

BAKER, J. T.; REDDY, V. R. Temperature effects on phenological development and yield of muskmelon. Annals of Botany, v. 87, n. 5, p. 605-613, 2001.

BARCELOS, M. D.; GARCIA, A.; MARCIEL JUNIOR, V. A. Análise de crescimento da cultura da batata submetida ao parcelamento da adubação nitrogenada em cobertura, em um Latossolo vermelho-amarelo. Ciência \& Agrotecnologia, v. 31, n. 1, p. 21-27, 2007.

BASTOS, E. A. et al. Parâmetros de crescimento do feijão caupi sob diferentes regimes hídricos. Engenharia Agrícola, v. 22, n. 1, p. 43-50, 2002.

BENINCASA, M. P. Análise de crescimento de plantas (noções básicas). 2. ed. Jaboticabal: Funep, 2003. 41 p.

CAIRO, P. A. R.; OLIVEIRA, L. E. M.; MESQUITA, A. C. Análise de crescimento de plantas. Vitória da Conquista: Edições UESB, 2008.

CARMO FILHO, F. do; OLIVEIRA, O. F. de. Mossoró: um município do semi-árido nordestino, caracterização climática e aspecto florístico. Mossoró: ESAM, 1995. 62 p. (Coleção Mossoroense, série B).

COSTA, L. C.; MORISON, J.; DENNETT, M. Effects of the weather on growth and radiation intercepted by Faba bean. Pesquisa Agropecuária Brasileira, v. 32, n. 3, p. 277-281, 1997.

EMPRESA BRASILEIRA DE PESQUISA AGROPECUÁRIA. Centro Nacional de Pesquisa de Solos. Sistema brasileiro de classificação de solos. 2. ed. Rio de Janeiro, 2006. 306 p.

EMPRESA BRASILEIRA DE PESQUISA AGROPECUÁRIA. Centro Nacional de Pesquisa de Solos. Manual de análises químicas de solos, plantas e fertilizantes. 2. ed. Rio de Janeiro, 2009.212 p.

FONTES, P. C. R.; DIAS, E. N.; SILVA, D. J. H. Dinâmica do crescimento, distribuição de matéria seca na planta e produção de pimentão em ambiente protegido. Horticultura Brasileira, v. 23, n. 1, p. 94-99, 2005.

FONTANA et al. Húmus, substâncias húmicas e a ciência do solo. In: ENCONTRO BRASILEIRO DE SUBSTÂNCIAS HÚMICAS, 7., 2007, Florianópolis, Anais... Florianópolis, 2007. p. 2.

GADIOLI, J. L. et al. Temperatura do ar, rendimento de grãos de milho e caracterização fenológica associada à soma calórica. Scientia Agricola, v. 57, n. 1, p. 377-383, 2000.

LIMA JÚNIOR, O. J. et al. Índices fisiológicos de melão cantaloupe "Torreon" cultivado com diferentes cores de mulch e lâminas de irrigação. Horticultura Brasileira. v. 22, n. 2, 2004. Suplemento. 1 CD ROM

MULLER, A. G.; BERTO, J. L.; TOLEDO, N. T. Modelagem Matemática do Acúmulo da Massa Seca em soja. In: CONGRESSO NACIONAL DE MATEMATICA APLICADA E COMPUTACIONAL, 30., 2007. Florianópolis. Anais eletrônicos... Florianópolis: SBMAC, 2007. Disponível em:< www.sbmac.org.br/eventos/cnmac/xxx_cnmac/PDF/87.pdf >. Acesso em: 22 maio 2011.

O'DONNELL, R. W. The auxin-like effects of humic preparations from leornadita. Soil Science, v. 116, n. 1, p. 106-112, 1993.

PACE, P. F. et al. Drought-induced Changes in Shoot and Root Growth of Young Cotton Plants. The Journal of Cotton Science, v. 3, n. 1, p. 183-187, 1999.

PRETT, S. Comparison of seasonal thermal indices for measurement of corn maturity in a prairie environment. Canadian Journal of Plant Science, v. 72, n. 1, p. 1157-1162, 1992.

SCHOFFER, R. S.; VOLPE, C. A. Relação entre a zona térmica efetiva e o crescimento da soja. Revista Brasileira de Agrometeorologia, v. 10, n. 1, p. 89-96, 2002.

SEGINER, I. Equilibrium and balanced growth of a vegetative crop. Annals of Botany, v. 93, n. 2, p. 127-139, 2004.

SILVA, M.C.C. et al. Produtividade de frutos do meloeiro sob diferentes níveis de salinidade de água de irrigação, com e sem cobertura do solo. Horticultura Brasileira, v. 23, n. 2, p. 202-205, 2005.

SILVA, R. M. et al. Produção de ácidos húmicos e fúlvicos a partir de diferentes matérias-primas orgânicas. Revista Escola de Engenharia, v. 23, n. 2, p. 53-60, 1995.

SILVA, R. M. et al. Desenvolvimento das raízes do azevém cultivado em solução nutritiva completa, adicionada de substâncias húmicas, sob condições de casa de vegetação. Revista Brasileira de Zootecnia, v. 29, n. 6, p. 1623-1631, 2000. 